\title{
Nature and Mixed Types Architecture for Milano Farini
}

\author{
Adalberto Del Bo, Maria Vittoria Cardinale, Martina Landsberger, \\ Stefano Perego, Giampaolo Turini and Daniele Beacco
}

\begin{abstract}
The project presented here, carried out within a research framework on abandoned railways areas in Milano, faces the issues of building an urban part by looking at the future city with particular attention to the themes of living into the relationship with nature. The project, starting from the analysis of the urban role of the area, gives relevance to the main directions built by the city construction and to the north-west direction of the city expansion. A central importance is given to the park as primary element of the urban structure made up by blocks not entirely surrounded by roads fostering a significant internal traffic reduction. The second element concerns the deep research content of building typological natural experiments and the character of originality achieved by further examination carried out on the plan and housing design, with attention also to the solution based on the typological contamination. The park displacement in the plan central area is the decisive event of the project in relation to the urban reference scheme of which persist the main lines and the urban step rhythm, considered the most significant architectural elements along with the twin towers located in north-west. The studies on the patio-houses settlement and on the multi-storey linear building enrich the variety of building forms and characters together with the design of the mosque as element of a multicultural and open new city.
\end{abstract}

Keywords Nature $\cdot$ Mixed types $\cdot$ Urban composition $\cdot$ Continuity $\cdot$ Tradition

\footnotetext{
A. Del Bo $(\varangle) \cdot$ M. Landsberger · D. Beacco

Architecture, Built Environment and Construction Engineering-ABC Department, Politecnico di Milano, Milan, Italy

e-mail: Adalberto.delbo@polimi.it
}

M. V. Cardinale $\cdot$ S. Perego $\cdot$ G. Turini

Milan, Italy 


\section{Introduction}

The project presented here, carried out within a research framework on abandoned railway areas in Milano, faces the issue of building an urban part by looking at the future city with particular attention to the themes of living and to the relationship with nature.

An important point concerns the identification of an urban structure made up by blocks not entirely surrounded by roads (located on three sides with the terminals as cul-de-sac) and directly connected to a large park located in a central position as an element of organization and order of the whole plan. ${ }^{1}$ The structure behaves with a significant internal traffic reduction and the possibility to reach the park and the public buildings without crossing roads. The structure of the settlement proposed is directly referred to the city idea drawn by Ludwig Hilberseimer, of which the project also offers the characteristic mixed housing typologies (in particular high-rise and low-rise buildings) able to achieve the required density.

The second element concerns the deep research content of building typological nature experiments (about which the next interventions deal) and the character of originality achieved by further examination carried out on the plan and housing design, with attention also to solutions based on typological contamination.

The park displacement in the plan central area is the decisive event of the project in relation to the urban reference scheme of which persist the main lines and the urban step rhythm, considered the most significant architectural elements along with the twin towers located north-west.

In this context, the assumption of the railroad direction as the main reference of the project guidelines in the north is a relief matter: indeed, the directions expressed by the dialectic of the different positions constitute a very important point of the urban project because through them, we tend to express an evaluation on the city and its constituent parts.

In the northern part of the Dergano-Bovisa area, the high level of disorder represents an element of uncertainty that is difficult to use as a reference, while in the south (beyond the railways), the confirmation to the Corso Sempione direction constitutes a substantial adhesion to the prevailing layout of the historical city (Fig. 1).

\footnotetext{
${ }^{1}$ Adalberto Del Bo, La costruzione di un'idea di piano. La nuova città oltre l'isolato, in La Casa, Milano 2013, a cura di G: Malacarne.
} 


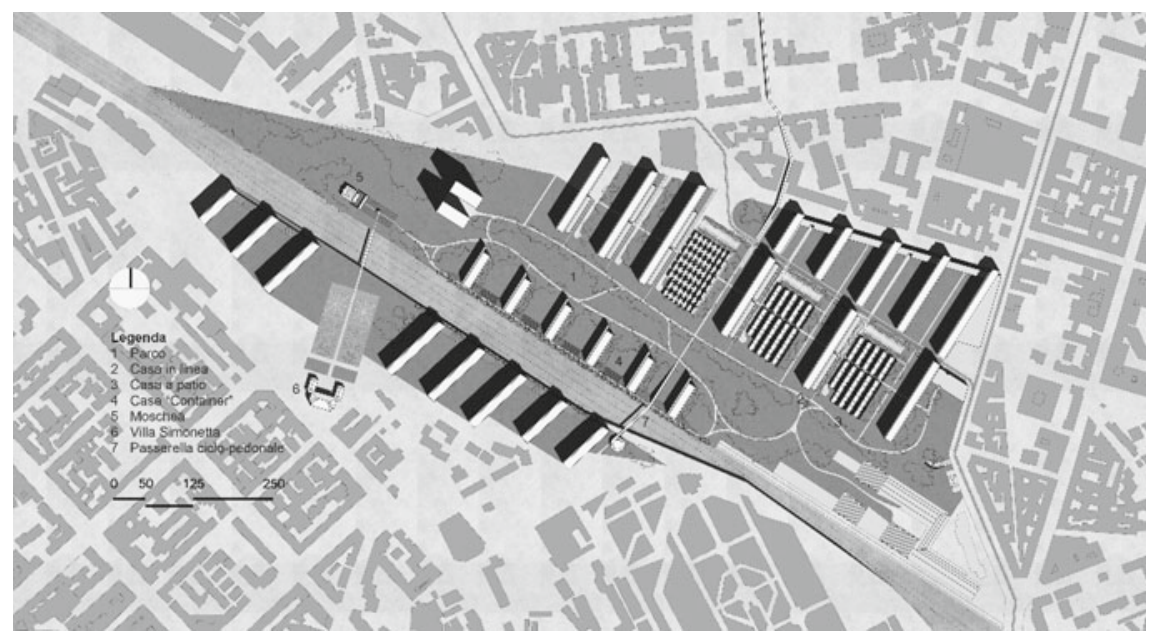

Fig. 1 Milano Farini. Site plan with shadows

\section{Patio-house: A Living Type}

"The architecture is placed in the space and at the same time encloses it. From this arises a double problem: the control of external and internal space (...)". These words by Ludwig Hilberseimer summarize the meaning of the project by Mies van der Rohe for a three-courtyard house. The project was designed, probably, from 1934. The theme is the development of a sort of single-family home prototype. The design consists of the definition of an enclosure within which the house is freely composed. The enclosure also defines the separation between the internal and private home space and, depending on the possible different locations, the natural or urban outdoor space.

Mies van der Rohe drawings describe the character of the project: an introverted building whose relationship with the outside is realized by a small, but necessary, entrance door; a uniform brick façade and a thin slab covering the interior space which - as we can see in the plan-occupies only a part of the enclosed garden.

Inside the enclosure, the T-shaped plan defines three courts, different in character and size, which establish different relationships with the parts of the house facing inside them. The large living room looks onto the space of nature that is a real walled garden, while the service areas look on the smaller and paved courtyards. In this way, from any point of the covered space it is possible to see the nature of the large green courtyard and the brick wall of the enclosure.

Representing a clear idea of dwelling, Mies, with few elements, defines the character and the size of his home.

Mies van der Rohe does not invent anything but, on the contrary, seeks in the history an analogous example to be repeated not so much for the form as for the validity of the general principle proposed. Probably, his reference is the Roman house 
in which the direct relationship with the city is denied in favour of the definition of a "different private world".

The Roman domus is, in fact, an introverted house in which the relationship with the urban space is realized only by the necessary entrance door.

The roman house is composed around the open space of the courtyard, an element of representation of the type and a necessary part from the functional point of view. The courtyard, in fact, is the place where the various rooms of the house overlook and from which they take light and air.

As in the Mies project, originally conceived as isolated and then composed to build blocks in the city, the idea of the domus is summed up in the construction of a separation wall between inside and outside. What is important is the representation of an idea of dwelling consisting in showing the "privacy" of the family life as opposed, and alternative, to the public life.

The project of the low houses aims to reinterpret similar historical examples according to new needs and requirements in term of quantity and urban dwelling quality.

In the specific case of the realization of a new urban part, the proposed ensemble of patio houses is defined through a brick wall considered as the element which makes the composition recognizable and measurable.

As proposed by Mies van der Rohe for the three-court houses, the wall surrounds one or more patios faced by individual households. The upper floor façades of the two-storey dwelling entertain long-distance relationship with the park in which the houses are placed. According to this point of view, the wall is that fixed element able to legitimize any formal and typological variation in the construction of the individual houses.

From the typological and morphological point of view, the design envisages the construction of high-density blocks consisting of two-storey row patio houses. According to the orientation and to the relationship with the block, the design suggests two-house types. The wooden structure and the 2.50 height is constant and needed in order to contain building costs and energy wastes, as shown by international legislations.

The first house type is a T-shaped faced south-east. The single-storey T-short side contains a living room overlooking two symmetrical courtyards. The second side, on two floors, consists of three modules of which the central one, with no windows, contains the staircase leading to the sleeping area on the upper floor and to the terrace placed on the roof of the living room below.

The houses are put together to form rows arranged according to the longitudinal direction of the block and facing the storey houses. This ensures both flexibilities in the setting of the house that can be enlarged lengthwise by adding constant modules, as well as a good exposure (south-east) and the cross-ventilation of the building.

A projecting element at the upper level acts as a sunscreen for the lower floor which is almost entirely windowed because of its relationship with the garden and its collective character. Upstairs, the windows are smaller and the projection becomes a small loggia. 
In order to arrange the houses to face the park crosswise to the block, the second type of low houses has been designed. The principle of structural flexibility and good orientation remains unchanged also in this case. The solution consists of two-storey row patio houses with south-east exposure. In consideration of the arrangement in the transverse direction of the block, the horizontal distribution of the house is located along the north-west wall, in order to guarantee full flexibility in the event of a possible extension.

The two-house types envisage wood as constructive system, both for the structure and the wall plug. This choice respects the actual requirements of flexibility, cost control, sustainability and speed of construction.

The intention to show the exposed structural system and the plug (the prefabrication system and the modular design allow a dry-stone construction) led to use wood as outer cladding too. The façade of the house is thus formed by a series of slats anchored to a steel structure to build a ventilated wall useful for the purpose of containment energy and durability of the building (Fig. 2).

(a)

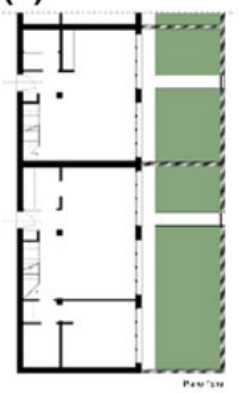

(b)
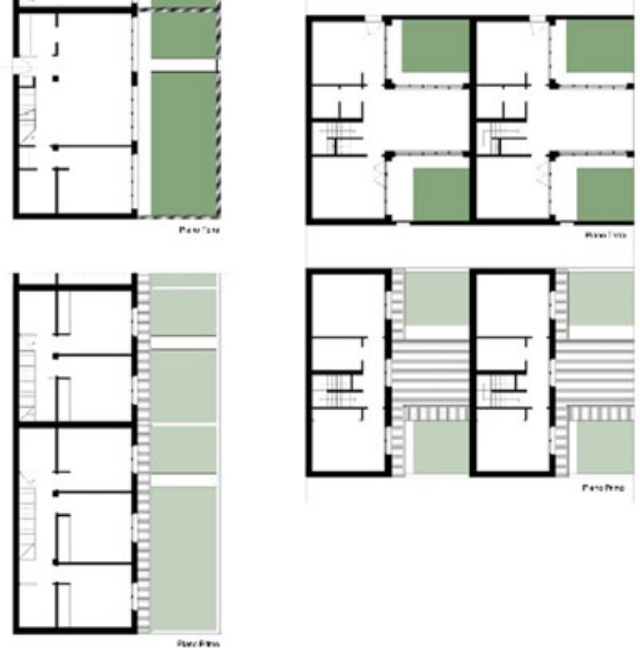

(c)
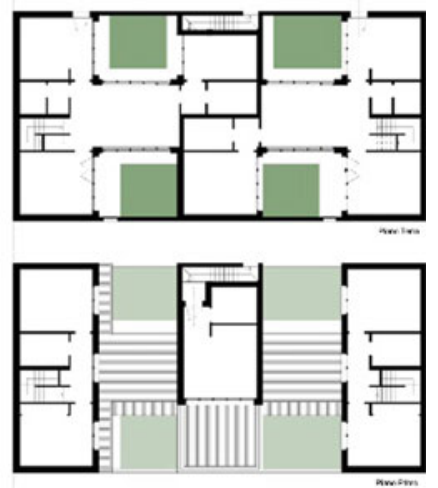

0

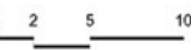

Fig. 2 Milano Farini. Patio-houses 


\section{Idea and Development of Multi-storey Linear Building}

The settlement unit designed for Scalo Farini is defined by two elements: the courtyard house and the multi-storey linear building. Both elements are designed with common aims that can be synthesized under the terms of flexibility and standardization.

The main reference about the building studied here is placed in the townhouses designed by Mies van der Rohe at Lafayette Park in Detroit.

The starting requirement consists of a possible overlapping of the Detroit block townhouses. The aim posed consists to achieve a solution formed by duplex apartments and provided with a corridor at alternate floors.

The interest towards Detroit's townhouses is due to the progress on the typological solution that is represented. It contains the traditional characters of the townhouses although shows an interesting solution about the bedroom distribution at the first floor related to the limits of the living room at the ground floor.

Through an ingenious solution of the façade subdivision in three parts, Mies van der Rohe reached a development of the type starting from the traditional characters of the townhouse.

An analogous solution, in terms of distribution, was studied by Josep Lluís Sert for Casa Bloc, in Barcelona, 1933. Also here, the apartments are duplex served with an internal small stair that leads to the room floor where Sert proposed a similar distributive solution that will adopted by Mies in Detroit but without the same clarity about the relationship with structure, façade partition and space.

This difference in term of measure among the living room and the upper bedrooms, however, is not contained in a clear drawing of the fronts as in the case of Detroit. In fact, in Casa Bloc this problem is masked. The façade of the Casa Bloc is drawn by horizontal strips of the lodges and horizontal windows. But the windows are not related to each room: for three rooms correspond two windows and one of it is placed across two rooms. In the drawing of townhouses, Mies contains the difference within a unified design where the relationship with the steel structure is inseparable to the spatial division of the dwelling.

The design of the multi-storey linear building comes from a philological process because it is based on the original building shape designed by Mies, redrawn through the analysis of the sources as, for example, Mies's Drawings Archives, thanks to the several surveys and the different reconstructions of the original Lafayette Park proposal carried out by our resource unit about this important settlement in the last decade. However, that process is not only concerned with the reproduction of the same building but tends to develop it in a progressive way starting to the clear and not-modifiable aspects of the reference.

The comprehension of the structural system of Lafayette townhouses, reproposed in this project, represents a fundamental passage for correct knowledge. Is necessary refer to two combined homes. The sketch posed on the text side is realized for this necessity. 
Mies, on the subdivision in three parts of the fronts, juxtaposed a subdivision in two parts in the main floor where are the living space that is symmetrical on the central wall division. This wall contains, in the extended measure of the stair, two pillars that sustain two beams posed in the longitudinal verse, perpendicularly to that wall.

Each living space measure $18^{\prime}$ width $(5.40 \mathrm{~m})-36^{\prime}(10.80 \mathrm{~m})$ referred to two combined unit. The vertical elements that subdivided into three parts the façade generate three rooms on the first floor. Although, the three-vertical elements support the "C" profile edge beam.

Related to the subdivision into three parts of the front rooms on the first floor taking a suitable size. Those dimensions would not be possible if the subdivisions of the bedrooms were strictly contained into the width of the living room below.

The overlapping of three duplexes (six floors) with $2.50 \mathrm{~m}$ storey height on a commercial basement had required a check of the general framework and a reshaping of the structural elements. Distribution is guaranteed by a steel corridor juxtaposed on the north-west side, while on the south-east side, with the same principle, there are lodges to protect the great window of the living and the bedrooms against the sunlight in the summertime. Each part juxtaposed are related to the building structure and have a structural measure of $1.80 \mathrm{~m}$.

\subsection{Students Dwelling. The Container Reuse}

Studying the student dwellings problem, instead, the group had followed a resource way marked by some European and extra-European experiences. Today, the container's reuse represents a vast interesting way of architectural resource to investigate as well shown by many realized example in north Europe. ${ }^{2}$

In Scalo Farini, the project is designed six buildings of which the width is obligated and corresponds to the maximum container standard, $40^{\prime}(12.20 \mathrm{~m})$. The second dimension is near $60 \mathrm{~m}$. On this building, in the same way of the buildings describes before, are been juxtaposed the corridor and the loggias. These buildings are posed perpendicularly to the public elevate promenade that defines the edge of the railway (Figs. 3 and 4).

\footnotetext{
${ }^{2}$ An interesting example of container's reuse is Keetwonen, in Amsterdam where, without the aid of any structural system (only particular elements in relation to the contact point of the containers) there are several five-storey buildings with distribution corridors and loggias realized with an autonomous steel structure. The depth corresponds to $12.20 \mathrm{~m}\left(40^{\prime}\right)$, height is $2.89 \mathrm{~m}\left(9^{\prime}\right)$ and the width is $2.43 \mathrm{~m}$ $\left(8^{\prime}\right)$.
} 

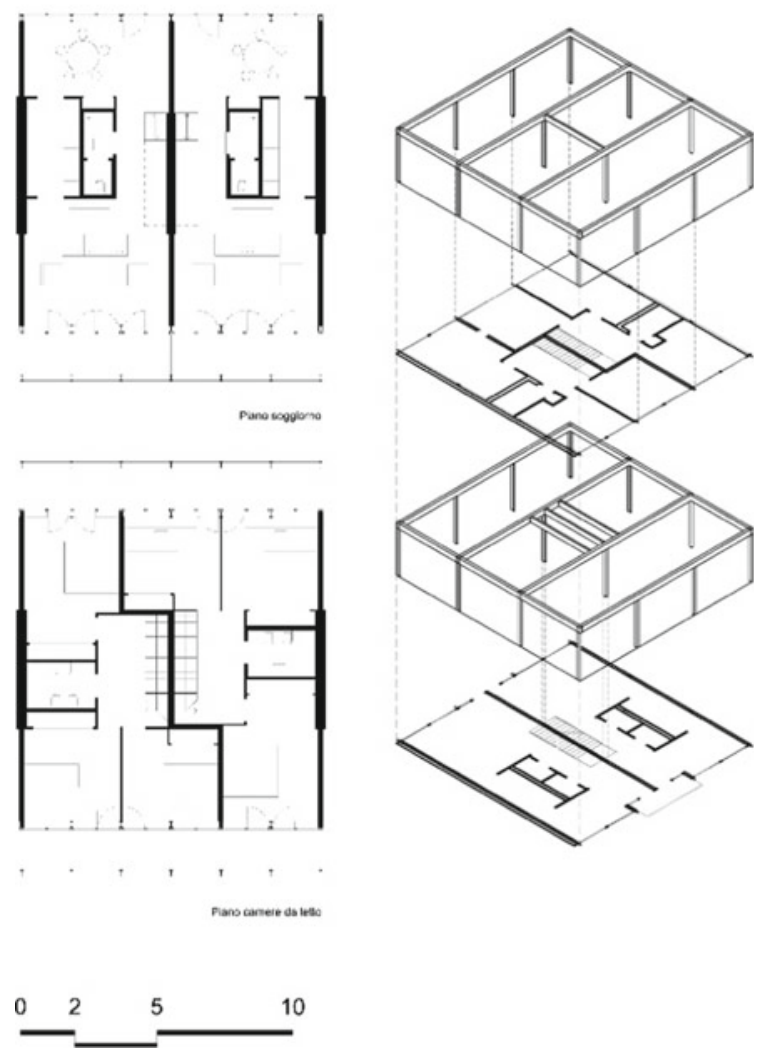

Fig. 3 Milano Farini. Multi-storey building

\section{Scalo Farini: Design of a Mosque}

Architectural studies regarding the morphological state of a mosque is an essential task that allows understanding of the design and building processes of ancient and contemporary artefacts. In an area where the existing structures dedicated to the Islamic community are sparse, the design of an Islamic holy place must include studies of similar cases from non-Islamic countries (especially in Europe and the USA) where many mosques have been built since the last century. The comparative study between contemporary and ancient mosques creates the opportunity of discovering the morphologically stable state of this place of worship. The religious artefact has to follow the direction of the Qibla (which is the direction of Mecca that houses the Islamic shrine of the Kaaba, towards which devotees must face during prayer) that in the case of the fortuitous rail yard known as Farini, corresponds exactly to the axis of the tracks as well as the reference lines of the new urban blocks. 


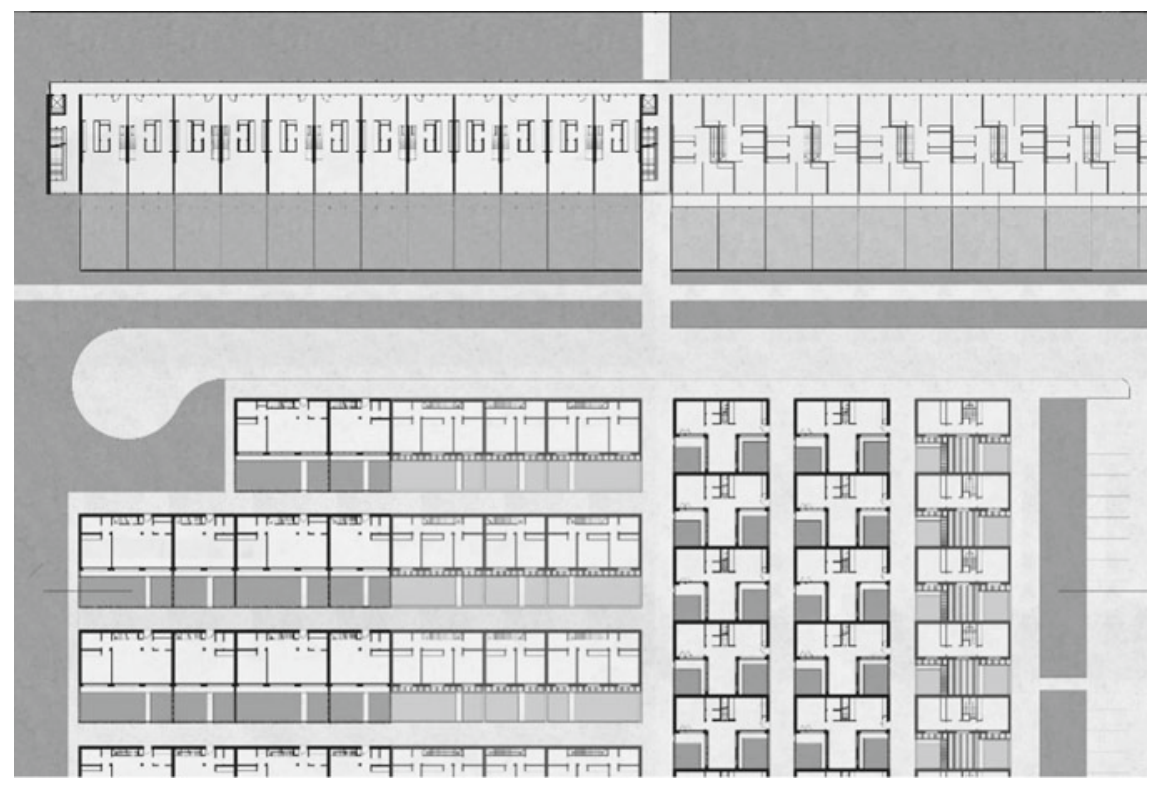

Fig. 4 Milano Farini. Typical floor

The greenery (located in the north-west area of the rail yard) creates a free disposition that makes the mosque similar to a pavilion, as a punctual element within a free and natural surrounding. The mosque has a rectangular plan, which consists of a large courtyard with two-side entrances. Found on both sides of this enclosed open space, it provides access to stores and services which are located in front of the main entrance. This space is arranged to create ablutions at the sides of the rooms (which are divided for men and women) for the necessary purification before prayer. The prayer area (musalla) is a square-shaped space that allows worshipers to be ordered in rows. The hypostyle hall consists of twenty-five pillars, of which a provision of five pillars on each side creates a central row that is used to support the vertical wooden panel that separates women from men in the same room. This space also allows spatial remodulation using portable panels between the pillars which can create confined areas for reading activities and studying.

Villa Simonetta and the mosque are similar in regard to their greenery area, which was designed by duplicating the original geometric pattern of Italian gardens whilst creating new green areas. The geographical and temporal aspects of the geometrical characteristics of the two completely different artefacts are related through the pedestrian path that connects the renaissance house, crosses the railway grounds and intercepts a fountain. 
Sustainability and energy conservation of the building is provided by the solar orientation of the openings. This analysis uses the details of these opaque parts and openings due to their inflexible direction towards the holy city of Mecca. The exchange of air and natural cooling is provided by openings found on the cover as well as a combined system of skylights and solar shading. This combined system is adjustable according to the change of seasons and inclination in order to decrease the heat load during the summer and to get extra heat loads during the winter.

Open Access This chapter is licensed under the terms of the Creative Commons Attribution 4.0 International License (http://creativecommons.org/licenses/by/4.0/), which permits use, sharing, adaptation, distribution and reproduction in any medium or format, as long as you give appropriate credit to the original author(s) and the source, provide a link to the Creative Commons license and indicate if changes were made.

The images or other third party material in this chapter are included in the chapter's Creative Commons license, unless indicated otherwise in a credit line to the material. If material is not included in the chapter's Creative Commons license and your intended use is not permitted by statutory regulation or exceeds the permitted use, you will need to obtain permission directly from the copyright holder. 